\title{
Article \\ FEC Additive for Improved SEI Film and Electrochemical Performance of the Lithium Primary Battery
}

\author{
Xuan Zhou ${ }^{\dagger}$, Ping Li ${ }^{\dagger}$, Zhihao Tang, Jialu Liu, Shaowei Zhang, Yingke Zhou * and Xiaohui Tian * \\ The State Key Laboratory of Refractories and Metallurgy, Institute of Advanced Materials and Nanotechnology, \\ College of Materials and Metallurgy, Wuhan University of Science and Technology, Wuhan 430081, China; \\ zhouxuan4321@outlook.com (X.Z.); JZLiPing@wust.edu.cn (P.L.); zhihaotang1@outlook.com (Z.T.); \\ JialuLiu@wust.edu.cn (J.L.); zhangshaowei@wust.edu.cn (S.Z.) \\ * Correspondence: zhouyk@wust.edu.cn (Y.Z.); txh@wust.edu.cn (X.T.); Tel./Fax: +86-27-68862928 (Y.Z.) \\ + These authors contributed equally to this work.
}

check for updates

Citation: Zhou, X.; Li, P.; Tang, Z.; Liu, J.; Zhang, S.; Zhou, Y.; Tian, X. FEC Additive for Improved SEI Film and Electrochemical Performance of the Lithium Primary Battery. Energies 2021, 14, 7467. https://doi.org/ $10.3390 /$ en14227467

Academic Editor: Cai Shen

Received: 15 October 2021

Accepted: 6 November 2021

Published: 9 November 2021

Publisher's Note: MDPI stays neutral with regard to jurisdictional claims in published maps and institutional affiliations.

Copyright: (c) 2021 by the authors. Licensee MDPI, Basel, Switzerland. This article is an open access article distributed under the terms and conditions of the Creative Commons Attribution (CC BY) license (https:// creativecommons.org/licenses/by/ $4.0 /)$.

\begin{abstract}
The solid electrolyte interphase (SEI) film plays a significant role in the capacity and storage performance of lithium primary batteries. The electrolyte additives are essential in controlling the morphology, composition and structure of the SEI film. Herein, fluoroethylene carbonate (FEC) is chosen as the additive, its effects on the lithium primary battery performance are investigated, and the relevant formation mechanism of SEI film is analyzed. By comparing the electrochemical performance of the $\mathrm{Li} / \mathrm{AlF}_{3}$ primary batteries and the microstructure of the $\mathrm{Li}$ anode surface under different conditions, the evolution model of the SEI film is established. The FEC additive can decrease the electrolyte decomposition and protect the lithium metal anode effectively. When an optimal 5\% FEC is added, the discharge specific capacity of the $\mathrm{Li} / \mathrm{AlF}_{3}$ primary battery is $212.8 \mathrm{mAh} \mathrm{g}^{-1}$, and the discharge specific capacities are respectively 205.7 and $122.3 \mathrm{mAh} \mathrm{g}^{-1}$ after storage for 7 days at room temperature and $55^{\circ} \mathrm{C}$. Compared to primary electrolytes, the charge transfer resistance of the $\mathrm{Li} / \mathrm{AlF}_{3}$ batteries with $\mathrm{FEC}$ additive decreases, indicating that $\mathrm{FEC}$ is a promising electrolyte additive to effectively improve the SEI film, increase discharge-specific capacities and promote charge transfer of the lithium primary batteries.
\end{abstract}

Keywords: fluoroethylene carbonate; lithium primary battery; lithium metal anode; solid electrolyte interphase; $\mathrm{LiF}$

\section{Introduction}

A lithium primary battery is an energy storage device with lithium metal or a lithium alloy as the anode and manganese dioxide, thionyl chloride, carbon fluoride, iron disulfide and aluminum trifluoride as the cathode materials. Lithium is the lightest metal, with a low relative density (half of water), a low potential $(-3.04 \mathrm{~V})$ and a high theoretical specific capacity (up to $3860 \mathrm{mAh} \mathrm{g}^{-1}$ ) [1-3]. Consequently, by combining a lithium anode with other advanced cathode materials, a specific energy of more than $400 \mathrm{Wh} \mathrm{kg}^{-1}$ can be easily obtained. Compared to rechargeable lithium batteries, lithium primary batteries play an important role in the electronic industry, automation devices, aerospace and military equipment under some special conditions, due to the portability, wide operating temperature, stable discharge performance and long storage life [4-7]; however, the chemical nature of lithium metal is very active, where it will react quickly and release hydrogen when it encounters water, causing great safety hazards. As such, non-aqueous electrolytes, including lithium inorganic compounds as lithium salts and organic substances as solvents, are usually used in lithium primary batteries. These lithium salts are usually $\mathrm{LiClO}_{4}, \mathrm{LiPF}_{6}$, $\mathrm{LiBF}_{4}, \mathrm{LiAsF}_{6}$, etc., and the generally used organic solvents are propylene carbonate (PC), ethylene glycol dimethyl ether (DME), dimethyl carbonate (DMC), ethylene carbonate (EC), acetonitrile (AN), tetrahydrofuran (THF) and 1,3-dioxolane (DOL) or their mixtures [8-11]; however, the unstable discharge capacity and storage performance, as well as safety issues 
caused by the harmful dendrites, volume changes, and solid electrolyte interphase (SEI) film instability, are still challenges for the further widespread commercialization of lithium primary batteries.

Various strategies have been proposed to solve the above problems, such as the surface coating of the lithium metal anode and the use of electrolyte additives [12]. A coated artificial SEI film with a high ionic conductivity can promote lithium ion transport and improve discharge performance, while the use of electrolyte additives is beneficial to adjust the in situ SEI film that is formed on the lithium anode surface to improve the storage performance of the lithium primary battery. The main principle of electrolyte film-forming additives is that during the reaction between the lithium and electrolyte, the additive molecule gains electrons at a higher reduction potential than the solvent molecule for forming a stable SEI film, thus preventing the electrolyte decomposition and improving the performance of the lithium primary battery [13]. Electrolyte additives do not change the properties of the electrolyte, but mainly act on the modification of the SEI layer, for example, a dense and more uniform SEI film with good mechanical properties that can resist volume deformation well, such that the battery can be used in long-term storage and maintain stability before use. Recently, experiments and theoretical studies have proved that the fluoroethylene carbonate (FEC) preferentially decomposes during the process of contact with the lithium metal and forms a SEI film containing the main component $\mathrm{LiF}$ and some small molecular organics [14-16]. This SEI film can effectively provide transport paths for lithium ions, reduce the generation of lithium dendrites, and increase the lithium ion battery performance. FEC is a well-known additive and has been widely researched in the field of rechargeable batteries, especially regarding the regulation of the passivation layer on the $\mathrm{Li}$ anode of lithium metal batteries [15,17]; however, there are few reports on the influence of FEC electrolyte additives on the lithium primary batteries, and the composition, structure, formation mechanism of the SEI film and the impact of FEC additive on the lithium primary battery performance are rarely reported.

Metal fluorides $\left(\mathrm{MF}_{\mathrm{x}}\right)$ are one of the most attractive cathode candidates for lithium batteries because of their high conversion potential and large specific capacity, and for the high ionic nature of $\mathrm{MF}_{3}$ cathodes, $\mathrm{FeF}_{3}, \mathrm{TiF}_{3}, \mathrm{VF}_{3}$ and $\mathrm{MnF}_{3}$ have been widely studied [18,19]. Aluminum fluoride $\left(\mathrm{AlF}_{3}\right)$ is a new type of promising cathode material with a high theoretical specific capacity ( $957 \mathrm{mAh} \mathrm{g}^{-1}$ ), abundant reserve and stable properties [20]. In this work, the lithium primary battery is assembled using $\mathrm{AlF}_{3}$ as the cathode, lithium metal as the anode and $1 \mathrm{M} \mathrm{LiPF}_{6}$ in dimethyl carbonate (DMC) and ethylene carbonate (EC) (1:1 in volume) with different contents of FEC as the electrolyte. The evolution of the SEI film and the influence mechanism of the FEC additive on the composition and structure of the SEI film formed on the lithium anode surface were systematically studied, and the effect of the SEI film on the long-term storage properties of the lithium primary battery was revealed. The discharge specific capacity and storage performance of lithium primary battery were improved by the addition of FEC. After adding $5 \%$ FEC to the commercial carbonate-based electrolyte, the assembled $\mathrm{Li} / \mathrm{AlF}_{3}$ primary battery displayed the highest discharge specific capacity of $212.8 \mathrm{mAh} \mathrm{g}^{-1}$. Even after storage for 7 days at room temperature and at $55^{\circ} \mathrm{C}$, the assembled $\mathrm{Li} / \mathrm{AlF}_{3}$ batteries could still deliver discharge specific capacities of 205.7 and $122.3 \mathrm{mAh} \mathrm{g}^{-1}$, respectively. Meanwhile, the SEI film models with and without the addition of FEC in the electrolyte were preliminary established. This research highlights the effect of the electrolyte additive on the SEI film and is of great significance to increase the safety and stability of the lithium primary battery, which may also provide insight to improve the storage performance and service life of rechargeable Li metal batteries.

\section{Materials and Methods}

A mixture of $\mathrm{AlF}_{3}$, Super-P and PVDF (mass ratio of 80:12:8) was ground and dispersed into N-methylpyrrolidone (NMP) to form a uniform slurry which was evenly coated on the $\mathrm{Al}$ foil and then dried for $5 \mathrm{~h}$ at $80^{\circ} \mathrm{C}$ in a vacuum oven before cutting into electrode pieces. Subsequently, the $\mathrm{AlF}_{3}$ cathode, lithium metal anode, porous polypropylene films 
separator (Celgard 2325) and commercial LB-301 electrolyte (1 M LiPF 6 in EC-DMC (1:1)) were used to assemble the 2032 coin cells in the glove box. In order to study the influence of storage time and temperature on the lithium primary batteries performance, the assembled coin cells were respectively stored at room temperature for 1 day and 7 days, and at $55^{\circ} \mathrm{C}$ for 7 days, named as the RT-1D, RT-7D and $55{ }^{\circ} \mathrm{C}-7 \mathrm{D}$ batteries.

FEC with different mass fractions (1\%, 5\%, and 10\%) was added to the LB-301 electrolyte and stirred to form the composite electrolytes. The 2032 coin cells were assembled in a similar way as above in the glove box, except that the composite electrolytes were used instead of the commercial electrolyte. The assembled coin cells were also stored at room temperature for 1 day and 7 days, named as X-RT-1D and X-RT-7D (X represents the ratio of FEC added, such as 1\% FEC, 5\% FEC and 10\% FEC) batteries.

An Apreo S HiVac scanning electron microscope (SEM) was used to explore the lithium anode surface morphology. An Escalab 250xi X-ray photoelectron spectrometer (XPS) was used to measure the valence states and a Nicolet Is50 Fourier transform infrared spectrometer (FT-IR) was used to analyze the functional groups of the SEI film on the surface of the lithium anode. Atomic force microscopy (AFM, Dimension Icon, Bruker, Billerica, MA, USA) was used to examine the roughness of Li metal anodes.

Charge and discharge tests were carried out with the Neware BTS (5 V, $50 \mathrm{~mA})$. The voltage window was $1.0 \sim 4.5 \mathrm{~V}$ for $\mathrm{Li} / \mathrm{AlF}_{3}$ batteries. Electrochemical impedance spectroscopy (EIS) data were recorded with the CHI660D electrochemical workstation (frequency range $100 \mathrm{kHz} 100 \mathrm{mHz}$, voltage disturbance of $5 \mathrm{mV}$ ).

\section{Results and Discussion}

\subsection{The Effect of Storage Temperature and Time on the SEI Film in Lithium Primary Batteries}

To study the influence of storage time and temperature on the formation of the SEI film on lithium metal in the lithium primary batteries, the surface morphologies of the original lithium metal and the lithium anodes used in the RT-1D, RT-7D, and $55^{\circ} \mathrm{C}-7 \mathrm{D}$ batteries were analyzed and are displayed in Figure 1. Obviously, the original lithium metal possesses a relatively smooth surface (Figure 1a). Generally, when the electrolyte is in contact with lithium metal, the organic solvent and $\mathrm{LiPF}_{6}$ in the electrolyte will be decomposed into organic lithium salts and inorganic lithium salts [21]. Figure 1b shows that the surface of lithium metal anode used in the RT-1D battery became more uneven, with some gullies after being stored at room temperature for 1 day, which may have been caused by the extrusion of the products generated by the reaction between the electrolyte in the cracks of lithium anode surface and lithium anode [22]. With the increase of storage time, inorganic lithium salts were found on the surface of the lithium anode used in RT-7D battery with gradually occurring deposits in the gullies of the organic lithium salts, which improves the flatness of SEI film (Figure 1c). In addition, lots of particles were found on the surface of the lithium anode used in the $55^{\circ} \mathrm{C}-7 \mathrm{D}$ battery stored at $55^{\circ} \mathrm{C}$ for 7 days (Figure 1d), which may be due to the intensified reaction between the electrolyte and the lithium anode at high temperature, resulting in a large number of inorganic lithium salts. These results indicate that the storage time and temperature can change the morphology and composition of SEI films, and probably affect the electrochemical properties of lithium primary batteries.

XPS characterization was used to confirm the compositions of the SEI films on the surfaces of lithium anodes used in the lithium primary batteries. As shown in Figure 2a, there were two peaks of $\mathrm{ROLi}(56.3 \mathrm{eV})$ and $\mathrm{ROCO}_{2} \mathrm{Li}(55.1 \mathrm{eV})$ in the spectra of $\mathrm{Li} 1 \mathrm{~s}$. According to the Equations (1) and (2), ROLi and $\mathrm{ROCO}_{2} \mathrm{Li}$ may originate from the decomposition reaction of EC and DMC solvent, leading to the relatively smooth surface (Figure 1b) [23]. As displayed in Figure 2b, the peak of $\mathrm{Li}_{2} \mathrm{CO}_{3}(54.2 \mathrm{eV}$ ) appeared with the increase of storage time, which could be due to a further decomposition reaction of $\mathrm{ROCO}_{2} \mathrm{Li}$ as in equation (3), while the peak of ROLi disappears, which may be ascribed to the coverage of plenty of $\mathrm{Li}_{2} \mathrm{CO}_{3}$ (Figure 1c). Compared to Figure $2 \mathrm{~b}$, the new peak of $\mathrm{LiF}(55.8 \mathrm{eV})$ appears and peak of $\mathrm{ROCO}_{2} \mathrm{Li}$ disappears in Figure 2c, indicating that the 
high temperature of $55^{\circ} \mathrm{C}$ accelerates the decomposition reaction of $\mathrm{EC}, \mathrm{DMC}$ and $\mathrm{LiPF}_{6}$ (as shown in Equations (1)-(4)) [24], resulting in the formation of both $\mathrm{Li}_{2} \mathrm{CO}_{3}$ and $\mathrm{LiF}$, consistent with the SEM image of Figure 1d.

$$
\begin{gathered}
2 \mathrm{C}_{3} \mathrm{H}_{4} \mathrm{O}_{3}+2 \mathrm{e}^{-}+2 \mathrm{Li}^{+} \rightarrow\left(\mathrm{CH}_{2} \mathrm{OCO}_{2} \mathrm{Li}\right)_{2}+\mathrm{CH}_{2}=\mathrm{CH}_{2} \\
\mathrm{C}_{3} \mathrm{H}_{6} \mathrm{O}_{3}+\mathrm{e}^{-}+\mathrm{Li}^{+} \rightarrow \mathrm{CH}_{3} \mathrm{OCO}_{2} \mathrm{Li}+\mathrm{CH}_{3} \text { or }\left(\mathrm{CH}_{3} \mathrm{OCO}+\mathrm{CH}_{3} \mathrm{OLi}\right) \\
\left(\mathrm{CH}_{2} \mathrm{OCO}_{2} \mathrm{Li}\right)_{2} \stackrel{\text { trace } \mathrm{H}_{2} \mathrm{O}}{\rightarrow} \mathrm{Li}_{2} \mathrm{CO}_{3}+3 \mathrm{CO} \\
\mathrm{LiPF}_{6}+\mathrm{H}_{2} \mathrm{O} \rightarrow \mathrm{LiF}+2 \mathrm{HF}+\mathrm{PF}_{3} \mathrm{O}
\end{gathered}
$$
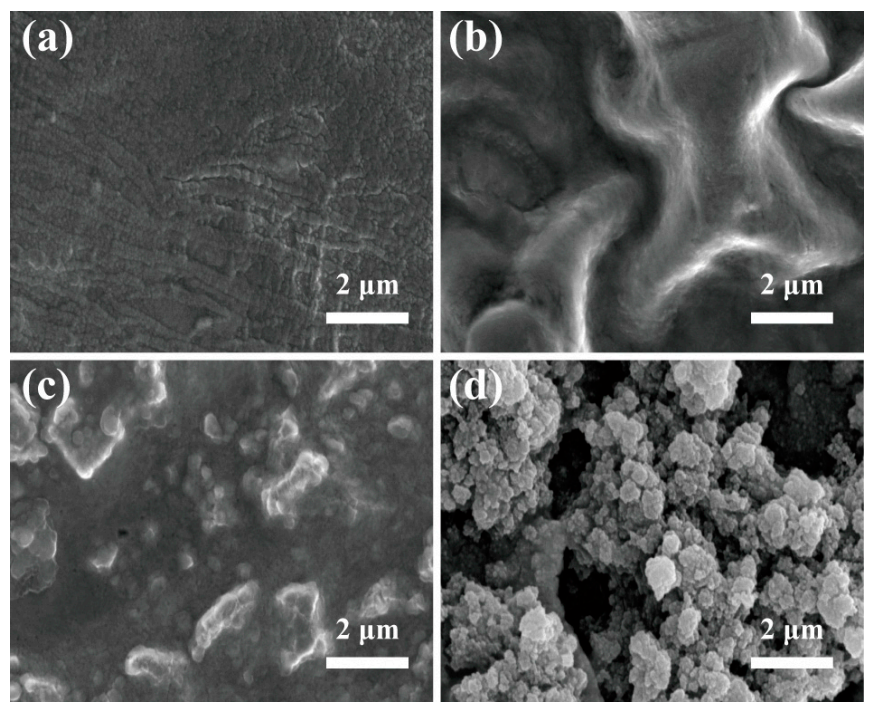

Figure 1. SEM images of lithium metal foils: (a) original; (b) RT-1D battery; (c) RT-7D battery; (d) $55^{\circ} \mathrm{C}-7 \mathrm{D}$ battery.
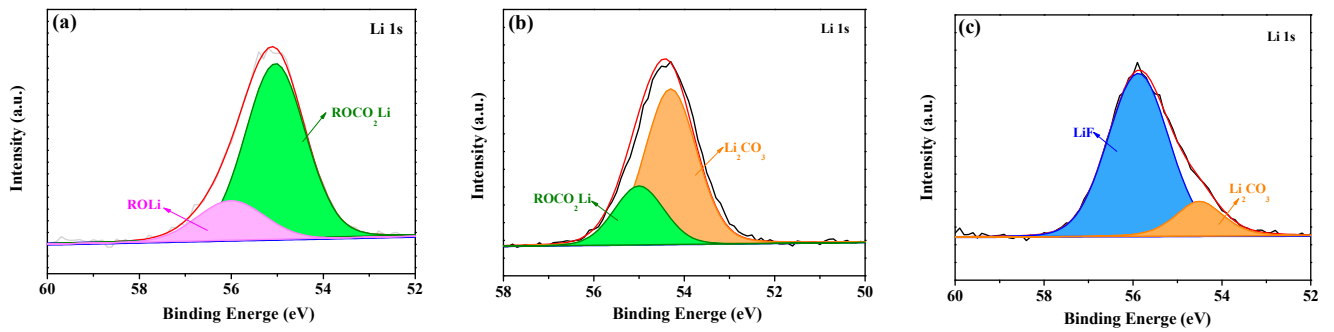

Figure 2. The XPS spectra for Li 1s: (a) RT-1D; (b) RT-7D; (c) $55^{\circ} \mathrm{C}-7 \mathrm{D}$ batteries.

EIS and discharge tests were carried out to analyze the impacts of various storage conditions on the electrochemical performance of the lithium primary batteries. As shown in Figure 3a, the distance from the origin to the left end of the semi-circular region is related to the battery internal resistance $\left(R_{\Omega}\right)$, which characterizes the transfer of lithium ions in the electrolyte. The diameter of the semi-circular region corresponds to the charge transfer resistance $\left(R_{\mathrm{ct}}\right)$, which characterizes the transfer of lithium ions in the SEI film [25]. The slope of the straight line from the right end of the semicircular is ascribed to the Warburg impedance, which characterizes the lithium ions diffusion within the bulk electrode. An equivalent circuit (inset of Figure 3a) was used to fit the EIS curves. The $R_{\mathrm{ct}}$ of the RT-1D battery was about $337.2 \Omega$, which is lower than that of RT-7D battery $(489.5 \Omega)$ and $55^{\circ} \mathrm{C}-7 \mathrm{D}$ battery $(636.1 \Omega)$. The increase of $R_{\mathrm{ct}}$ in both RT-7D and $55^{\circ} \mathrm{C}-7 \mathrm{D}$ batteries may be caused by the continuous accumulation of inorganic components with poor electrical conductivity in the SEI film on the electrode surface as the storage time and temperature increase [26]. The discharge specific capacities at $0.01 \mathrm{C}$ for the RT-1D, RT-7D and $55^{\circ} \mathrm{C}-7 \mathrm{D}$ batteries in Figure $3 \mathrm{~b}$ were $57.4,43.5$ and $28.2 \mathrm{mAh} \mathrm{g}^{-1}$. With the increase of the storage time 
and temperature, the specific discharge capacity of the battery also decreased (Figure $3 b$ ) and the discharge platform voltage reduced from $2.25 \mathrm{~V}$ to $2 \mathrm{~V}$, which was caused by the accumulation of reaction products in the SEI film and is consistent with the EIS results. These results indicate that the storage time and temperature can change the decomposition degree of EC, DMC and $\mathrm{LiPF}_{6}$, thus adjusting the component and structure of SEI film on the lithium anode surface, and further affecting the electrochemical performance of lithium primary batteries.
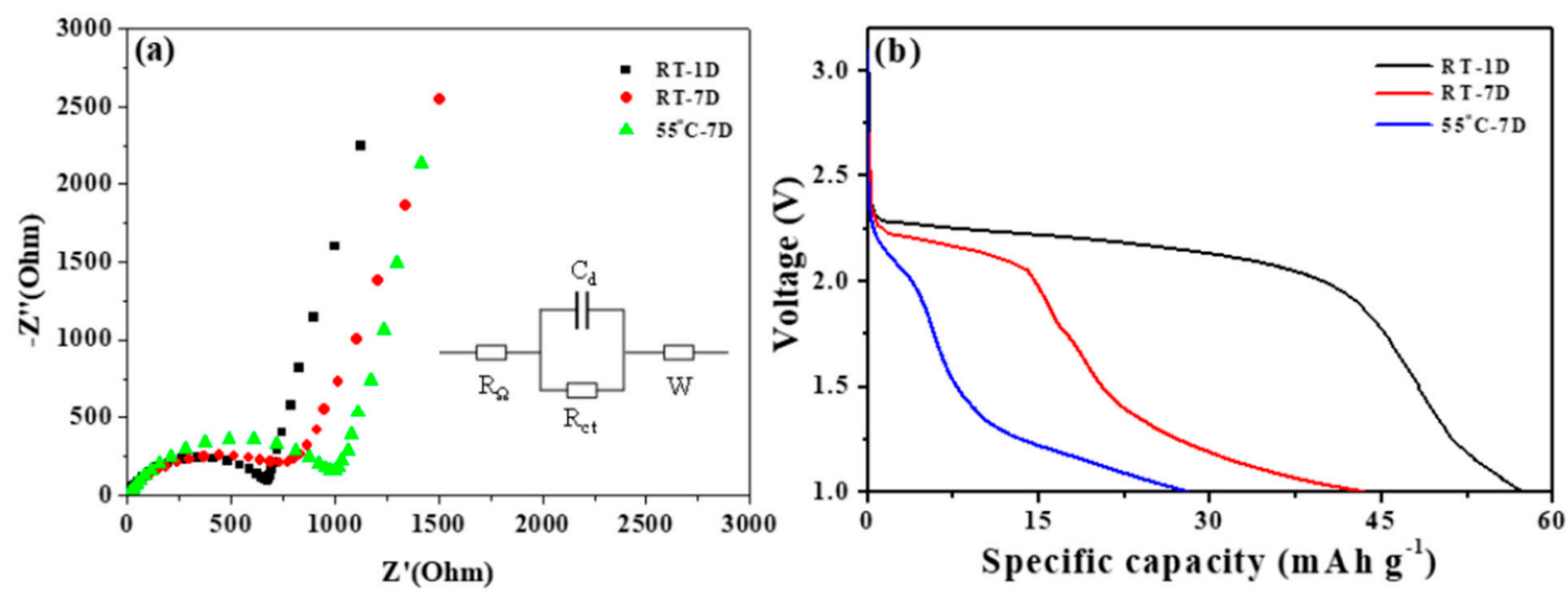

Figure 3. The EIS curves before the discharge test (a) and the discharge curves (b) of the RT-1D, RT-7D and 55 ${ }^{\circ} \mathrm{C}-7 \mathrm{D}$ batteries. The inset in (a) is the corresponding equivalent circuit.

\subsection{The Influence of FEC Additive on the SEI Film and Lithium Primary Battery Performance}

FEC additives of different contents were added to the commercial electrolyte (1 M $\mathrm{LiPF}_{6}$ in 1:1 EC-DMC) to optimize the composition of the SEI film. After adding FEC in the electrolyte, the FEC gains electrons ahead of the EC and DMC solvents to proceed with the reduction reaction and generates $\mathrm{LiF}$ and small molecular organics [27]. As such, the addition of FEC is expected to prevent the decomposition of both the EC and DMC solvents and adjust the composition of the SEI film.

As shown in Figure $4 a$, after adding 1\% FEC to the commercial electrolyte, fewer cracks on the lithium anode surface could be observed when compared to the lithium anode used in the commercial electrolyte (as shown in Figure 1b). According to the above-mentioned reaction mechanism, the original cracks on the lithium anode surface may be filled by large amounts of the inorganic and organic products of the reaction between the lithium anode and FEC, especially for the inorganic LiF. The instable organic products will decompose into $\mathrm{Li}_{2} \mathrm{CO}_{3}$ in the SEI film, which further decomposes into $\mathrm{CO}_{2}$. The production of gas will make the organic layer of the SEI film loose and porous, leading to filling with $\mathrm{LiF}$ particles [28]. After adding 5\% of FEC to the commercial electrolyte, more decomposed products via the reaction of FEC and lithium metal can fill the cracks on the surface of the metal lithium. Consequently, compared to the SEM image of Figure 4a, the lithium anode in Figure $4 \mathrm{~b}$ exhibits a more compact surface morphology. As shown in Figure 4c, a large number of aggregated particles unevenly cover the surface of lithium metal, which may be ascribed to the uneven deposition of a large number of products by the reaction of excessive FEC with lithium metal on the surface and in the cracks of lithium metal, thus resulting in the non-uniform deposition of subsequent $\mathrm{Li}_{2} \mathrm{CO}_{3}$ on the $\mathrm{LiF}$ and part of the organic layer. With an increasing storage time, a similar morphological evolution can be observed from Figure S1a-c, further demonstrating that the change of FEC content can regulate the morphology and composition of the SEI film on the lithium metal surface. 

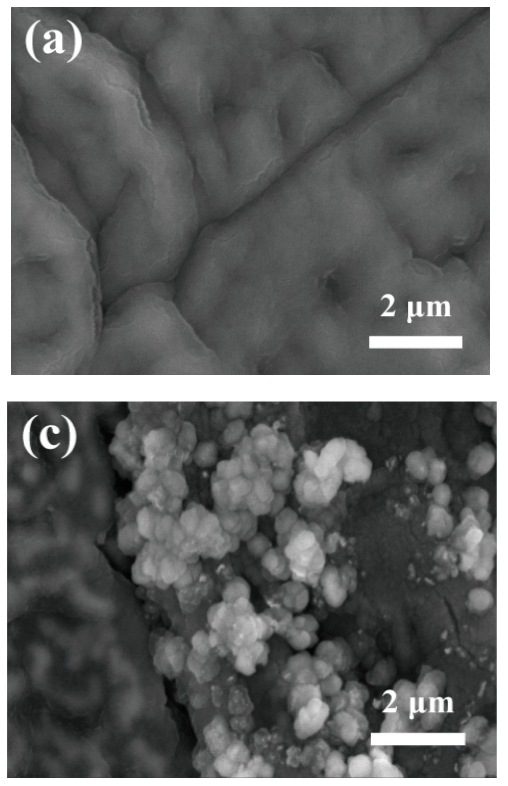
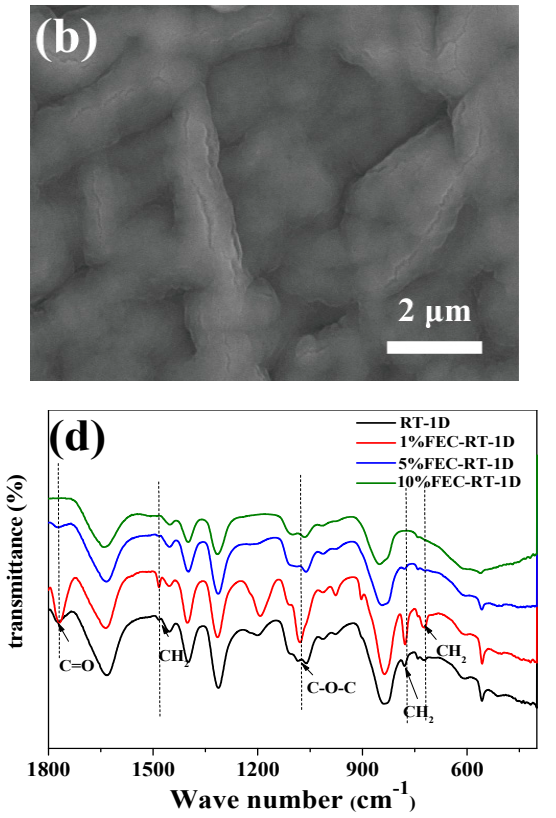

Figure 4. SEM images of lithium anodes: (a) 1\%FEC-RT-1D, (b) 5\%FEC-RT-1D and (c) 10\%FEC-RT1D batteries; (d) FT-IR spectra of lithium anodes used in RT-1D, 1\%FEC-RT-1D, 5\%FEC-RT-1D and 10\%FEC-RT-1D batteries.

Figure $4 \mathrm{~d}$ shows the FT-IR spectra of the lithium anodes reacted with the different contents of FEC added electrolytes. Obviously, the absorption peaks of RT-1D battery appeared at $725 \mathrm{~cm}^{-1}, 766 \mathrm{~cm}^{-1}$ and $1484 \mathrm{~cm}^{-1}$ (marked with dashed lines), which can be attributed to the in-plane swing and deformation vibration of the $-\mathrm{CH}_{2}$ bond [29]. The peaks located at $1195 \mathrm{~cm}^{-1}$ and $1770 \mathrm{~cm}^{-1}$ are caused by the antisymmetric stretching of the $\mathrm{C}-\mathrm{O}-\mathrm{C}$ bond and the stretching of the $\mathrm{C}=\mathrm{O}$ bond, respectively [30]. These absorption peaks indicate the existence of organic products caused by the decomposition of electrolyte or reaction with lithium metal. Some other peaks appeared in Figure $4 \mathrm{~d}$ may be the interference peaks caused by water, oxygen, and carbon dioxide in the air during the test. After the addition of FEC, parts of the characteristic peaks of the organic products shift, which may be caused by the replacement of $\mathrm{H}$ in organic products by $\mathrm{F}$ during the decomposition of FEC [31]. Meanwhile, after the addition of the $1 \%$ and 5\% FEC additives, the absorption peaks of organic products become weaken. Especially, when the content of the FEC additive increased to $10 \%$, parts of the absorption peaks of organic products even disappeared, indicating a decrease in organic products, which may be caused by the coverage of inorganic products originated from the reaction between excessive FEC and lithium metal.

XPS characterization was used to further verify the composition and content of the surface of the SEI film. In Figure 5a,b, only the ROLi (56.3 eV) and $\mathrm{ROCO}_{2} \mathrm{Li}(55 \mathrm{eV})$ peaks appear in the Li 1s peak (similar to Figure 2a). This may be due to the fact that the $\mathrm{LiF}$ particles that originated from the reaction between the added FEC and lithium metal were deposited into the porous structure of SEI film and were undetectable on the surface. In Figure $5 c$, the ROLi peak disappears and is replaced by the $\mathrm{Li}_{2} \mathrm{CO}_{3}$ peak $(54.2 \mathrm{eV})$, which can be ascribed to the coverage of $\mathrm{Li}_{2} \mathrm{CO}_{3}$ produced by the decomposition of the organic $\mathrm{ROCO}_{2} \mathrm{Li}$ on the surface of organic layer. These results indicate that the main organic components on the lithium metal surface are still $\mathrm{ROLi}$ and $\mathrm{ROCO}_{2} \mathrm{Li}$ after adding $\mathrm{FEC}$ in the commercial electrolyte; however, if the FEC content is too high, it will react with the lithium anode to produce excess $\mathrm{LiF}$, which will accumulate on the lithium metal surface, causing the subsequent decomposition product $\mathrm{Li}_{2} \mathrm{CO}_{3}$ to deposit unevenly on $\mathrm{LiF}$, thus showing the exposed $\mathrm{Li}_{2} \mathrm{CO}_{3}$ particles on the SEI film surface. This is consistent with the previous SEM investigation (Figure 4c). 

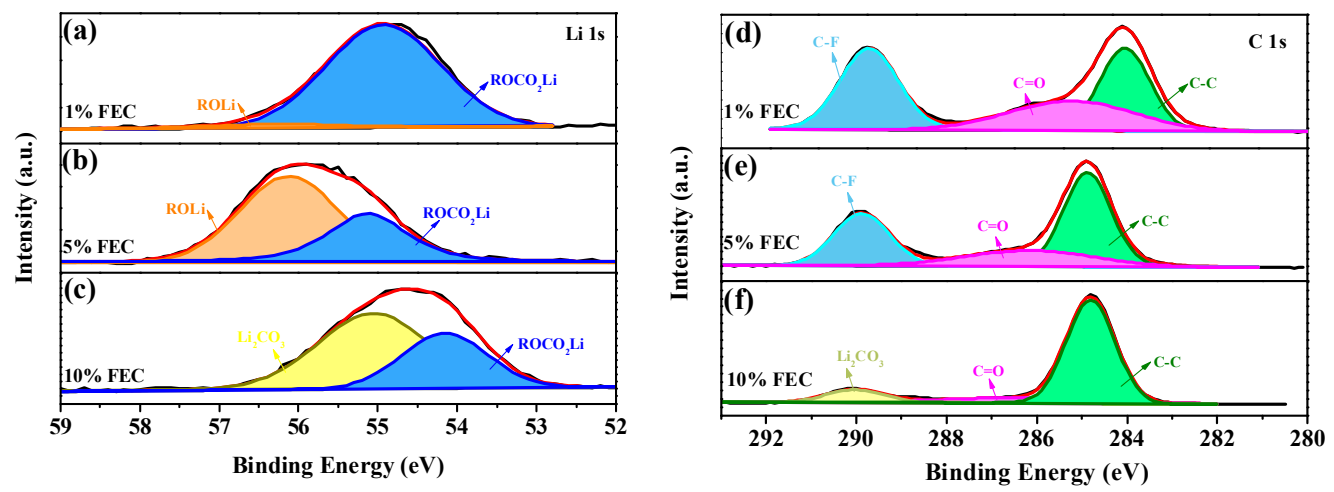

Figure 5. XPS spectra of Li 1s and C 1s in 1\% FEC-RT-1D battery (a,d), 5\% FEC-RT-1D battery $(\mathbf{b}, \mathbf{e})$ and $10 \%$ FEC-RT-1D battery $(\mathbf{c}, \mathbf{f})$.

Accordingly, the C-F $(290.1 \mathrm{eV}), \mathrm{C}=\mathrm{O}(285.9 \mathrm{eV})$ and C-C $(284.8 \mathrm{eV})$ peaks of the $\mathrm{C} 1 \mathrm{~s}$ spectra appear in Figure 5d,e; however, the C-F peak disappears and is replaced by the peak of $\mathrm{Li}_{2} \mathrm{CO}_{3}(290.2 \mathrm{eV})$ in Figure $5 \mathrm{f}$, which is also due to the coverage of $\mathrm{Li}_{2} \mathrm{CO}_{3}$ caused by the decomposition of $\mathrm{ROCO}_{2} \mathrm{Li}$. The added FEC can precede the electrolyte components of the decomposition, thus replacing them as the main source of F-C formation and inhibiting the decomposition of the electrolyte [32], which is beneficial to increase the lithium primary battery performance. When the content is increased to $10 \%$, the FEC will react with lithium metal, causing too many inorganic products to be deposited on its surface, thereby covering the organic layer, which is consistent with the above SEM and FT-IR analyses.

Atomic force microscopy (AFM) was used to evaluate the roughness and flatness of the SEI film on $\mathrm{Li}$ anode from $\mathrm{Li} / \mathrm{AlF}_{3}$ batteries both with and without the FEC additive. As shown in Figure 6a, the surface of the original fresh Li foil is composed of some agglomerated particles. Figure $6 \mathrm{~b}$ shows that the surface of the Li anode disassembled from the RT-1D battery is covered by some small particles formed by the decomposition of electrolyte, indicating that the SEI layer formed on the Li anode surface without the additive is not uniform and compact [33]. In contrast, the surface of the lithium anode from the 5\% FEC-RT-1D battery is composed of far smaller particles and became far more uniform and denser, as shown in Figure 6c. From the three-dimensional morphologies of Figure $6 \mathrm{~d}-\mathrm{f}$, the root-mean-square roughness $\left(\mathrm{R}_{\mathrm{q}}\right)$ and average roughness $\left(\mathrm{R}_{\mathrm{a}}\right)$ of original lithium metal foil, Li metal anode from RT-1D battery and Li metal anode from the 5\% FEC-RT-1D battery were respectively $20.1 \mathrm{~nm}$ and $16.4 \mathrm{~nm}, 15.2 \mathrm{~nm}$ and $12.0 \mathrm{~nm}$ and 7.8 $\mathrm{nm}$ and $5.9 \mathrm{~nm}$, further indicating that the roughness of the Li anode surface of the $5 \%$ FEC-RT-1D battery was greatly decreased and the formed SEI layer was far more uniform. Consequently, when the 5\% FEC additive was introduced in the electrolyte, the surface of the Li anode of the lithium primary battery after storage was uniformly covered by the dense and uniform SEI film, and the battery performance is thus expected to improve from the reduced corrosion and increased protection of the Li anode.

To verify the protective effect of the FEC additives on the lithium anode and the positive impact on the lithium primary battery performance, the corresponding EIS and discharge specific capacities were measured and are shown in Figure 7. Figure 7a,b show the $R_{\mathrm{ct}}$ values of the lithium primary batteries with different FEC additives before the discharge test. The $R_{\mathrm{ct}}$ values of lithium primary batteries RT-1D, $1 \%-\mathrm{RT}-1 \mathrm{D}, 5 \%-\mathrm{RT}-1 \mathrm{D}$ and 10\%-RT-1D were 665, 377, 396 and $681 \mathrm{ohms}$, respectively. After adding 1\% and 5\% FEC to the commercial electrolyte, the change in $R_{\mathrm{ct}}$ was significantly reduced, indicating that an appropriate addition of FEC can control the composition of the SEI film produced on the surface of lithium anode and optimize the $R_{\mathrm{ct}}$ value of the lithium primary batteries; however, the addition of $10 \%$ FEC increases the $R_{\mathrm{ct}}$ value of the lithium primary battery. This phenomenon might originate from the fact that the reaction of excessive FEC with the lithium anode greatly increases the formation of organic and inorganic products, making the transmission of lithium ions more difficult, thereby increasing the charge transfer 
resistance and reducing the discharge specific capacity of the lithium primary battery. The discharge specific capacities shown in Figure 7c further verify this point. The results indicate that the FEC additives can effectively increase the discharge specific capacities of lithium primary batteries due to a greater number LiF particles originating from the decomposition of the FEC compared with commercial electrolyte, which can conduct lithium ions more easily than organic products due to their lithophilic nature [34,35]. When the addition of FEC increased from $1 \%$ to $5 \%$, the discharge specific capacity at $0.01 \mathrm{C}$ of the lithium primary batteries increased from 93.0 to $212.8 \mathrm{mAh} \mathrm{g}^{-1}$, but when the FEC content further increased to $10 \%$, the excessive FEC reacts with the lithium anode to produce more unstable organic products which can be decomposed into $\mathrm{Li}_{2} \mathrm{CO}_{3}$ and $\mathrm{CO}_{2}$ on the lithium metal surface, making the organic layer of the SEI film looser and more porous and thus unable to effectively protect the metal lithium. In addition, the continuous progress of the reaction will cause the continuous accumulation of products, thicken the SEI film and extend the migration distance of $\mathrm{Li}^{+}$on the lithium anode surface during the discharge test. As such, the 10\% FEC-RT-1D battery displays a decreased discharge specific capacity of $23.0 \mathrm{mAh} \mathrm{g}^{-1}$ compared to that of the 5\% FEC-RT-1D battery. As shown in Figure 7d, the specific discharge capacities of the $5 \%$ FEC-RT-1D, $5 \%$ FEC-RT-7D and $5 \%$ FEC-55 ${ }^{\circ} \mathrm{C}-7 \mathrm{D}$ batteries were 212.8, 205.7 and $122.3 \mathrm{mAh} \mathrm{g}^{-1}$. As such, an appropriate addition of FEC in the commercial electrolyte can contribute a protective effect on the lithium metal, thus improving the electrochemical performance of the lithium primary battery.
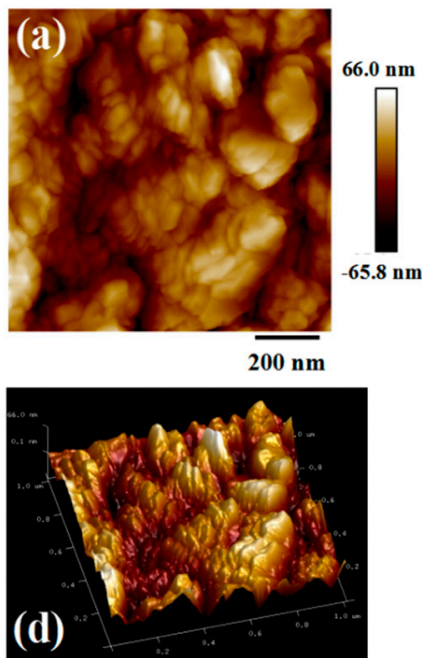

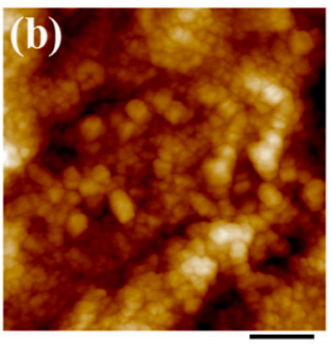

$200 \mathrm{~nm}$

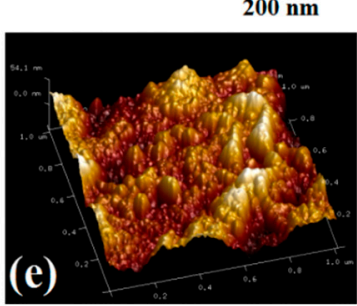

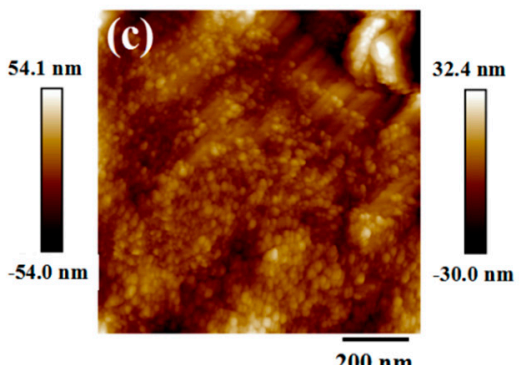

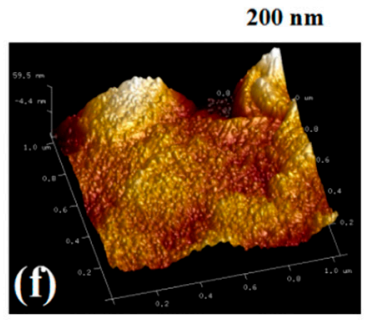

Figure 6. AFM images of the lithium metal foils: (a,d) original; (b,e) RT-1D battery; and (c,f) 5\% FEC-RT-1D.

In order to further verify the composition distribution inside the SEI films of the RT-7D and 5\% FEC-RT-7D batteries, corresponding X-ray photoelectron spectroscopy (XPS) depth curves were collected and are shown in Figures S2 and 8. Figure S2a,b display the relationship between the etching depth and atomic concentration distribution in the SEI film of the lithium metal anode. Within the top $10 \mathrm{~nm}$ etching depth, the $\mathrm{C}$ content in the SEI layer decreases sharply, corresponding to the decrease of organic components in SEI [36]. As the etching depth continues to increase, the contents of C, F, O and Li elements in the inorganic layer become stable, as shown in Figure S2b. The $C$ 1s and Li 1s spectra (Figure S2c,d) indicate that the surface of SEI film is mainly composed of $\mathrm{ROCO}_{2} \mathrm{Li}$ (C 1s: $285.9 \mathrm{eV}$ and Li 1s: $55 \mathrm{eV}$ ) and ROLi (Li 1s: $56.3 \mathrm{eV}$ ) organic species. After removing the top layer of the SEI film, the signal of $\mathrm{ROCO}_{2} \mathrm{Li}$ in C 1s disappears, but another peak representing $\mathrm{CO}_{3}{ }^{2-}$ appears at $290.2 \mathrm{eV}$. Correspondingly, the main species in $\mathrm{Li} 1 \mathrm{~s}$ have changed from $\mathrm{ROLi}$ and $\mathrm{ROCO}_{2} \mathrm{Li}$ in the top surface layer to $\mathrm{Li}_{2} \mathrm{CO}_{3}(54.6 \mathrm{eV})$ and $\mathrm{LiF}$ $(55.8 \mathrm{eV})$ under the top layer [37]. Meanwhile, the LiF content shown in Figure S2e first increases and then decreases as the depth of the SEI film increases. Thus, it can be inferred 
that the outermost part of the SEI film on the lithium anode surface of RT-7D battery is a fluffy organic layer (mainly lithium alkyl carbonate), where the adjacent component of the organic product is $\mathrm{LiF}$ layer and the inner part of $\mathrm{LiF}$ layer near lithium metal is a layer of $\mathrm{Li}_{2} \mathrm{CO}_{3}$ (Figure 9a).
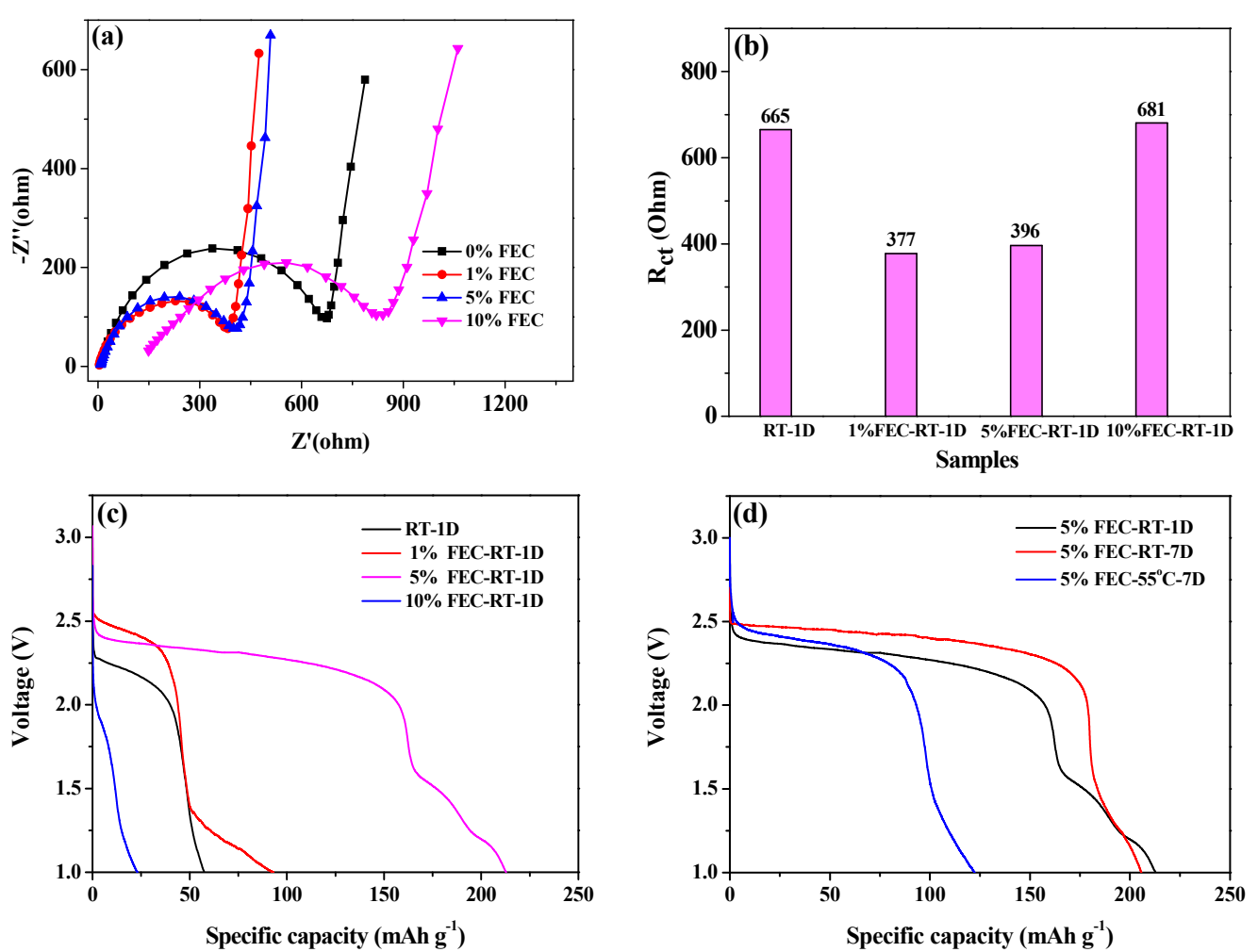

Figure 7. (a) The EIS plots, (b) Rct values, and (c,d) discharge curves of the lithium primary batteries with different FEC additives.

Similarly, Figure 8a,b show the relationship between the etching depth and the atomic concentration distribution of the SEI film in the FEC-RT-7D battery. The C content in the SEI film shows a sharp decrease in the first $10 \mathrm{~nm}$ depth and gradually remains stable, indicating a gradual decrease of the organic component in the SEI film. In addition, the inorganic components including $\mathrm{LiF}$ and $\mathrm{Li}_{2} \mathrm{CO}_{3}$ gradually increase with the increase of the etching depth. Detailed analyses of the $\mathrm{C} 1 \mathrm{~s}$ and $\mathrm{Li} 1$ s spectra are shown in Figure $8 \mathrm{c}, \mathrm{d}$, and the results indicate that the SEI film surfaces are mainly composed of organic $\mathrm{ROCO}_{2} \mathrm{Li}$ and ROLi components. In the subsequent etching, the $\mathrm{ROCO}_{2} \mathrm{Li}$ peak disappeared in $\mathrm{C} 1 \mathrm{~s}$, confirming the disappearance of the organic layer and the appearance of the inorganic layer at this time. Similarly, the dominant substances in the Li 1s spectrum change from ROLi and $\mathrm{ROCO}_{2} \mathrm{Li}$ to $\mathrm{Li}_{2} \mathrm{CO}_{3}$ and $\mathrm{LiF}$. Combining the change of $\mathrm{LiF}$ content in Figure 8e, it can be found that the percentage of $\mathrm{LiF}$ content first decreases and then increases with the increased etching depth, indicating that it is mainly distributed on the side of the SEI film near the organic layer and on the side near the lithium metal, which is consistent with the SEM characterization.

From the XPS characterization and FT-IR, it can be deduced that the SEI film on the surface of lithium anode of 5\% FEC-RT-7D battery can be described by a fluffy organic layer (mainly alkyl lithium carbonate) on the outer side, while the inorganic layer can be roughly divided into three layers, with $\mathrm{Li}_{2} \mathrm{CO}_{3}$ in the middle part and $\mathrm{LiF}$ layer on the side near the organic layer and on the side near the lithium metal (as shown in Figure 9b). The high LiF content of the SEI film can reduce the impedance of the electrode interface film and effectively reduce the diffusion impedance of $\mathrm{Li}^{+}$, thus increasing the performance of the lithium primary battery [17]. 

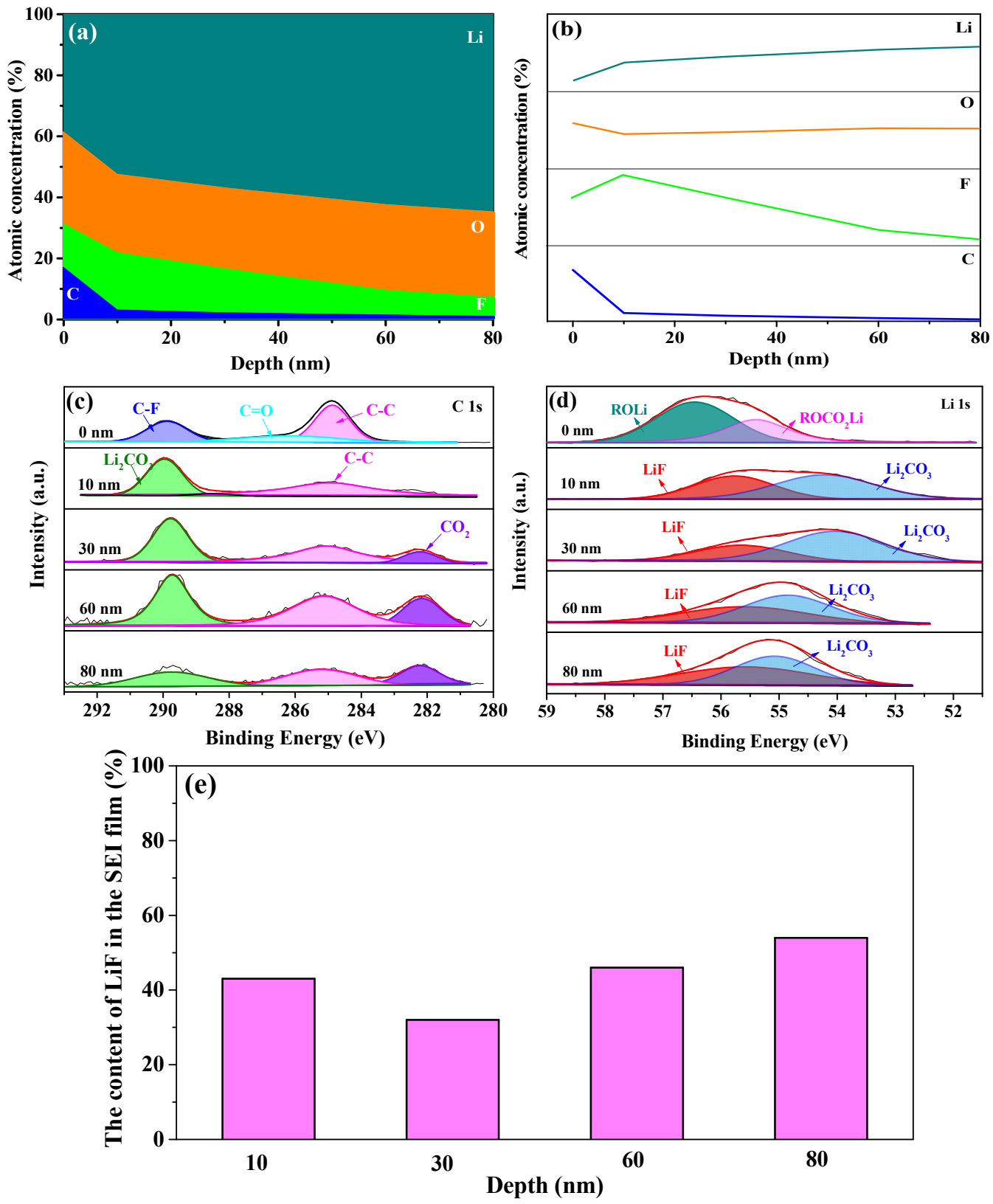

Figure 8. The surface chemistry of the 5\% FEC-RT-7D battery investigated by XPS. The evolution profiles of the (a) atomic percentages and (b) relative elemental intensities along the depth direction are shown. XPS spectra of (c) C 1s and (d) Li 1s along the depth direction. (e) The distribution of LiF along the depth direction. 
(a)

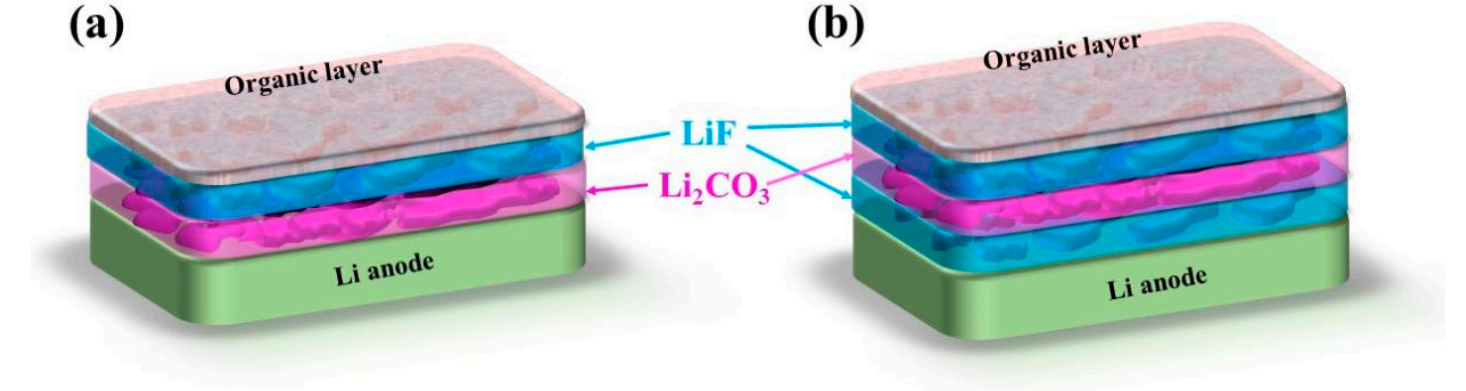

Figure 9. Schematic diagram of SEI film formation on the lithium metal anode with the FEC additive: SEI film model generated by the reaction between lithium metal with commercial electrolyte (a) and 5\% FEC (b).

\section{Conclusions}

In summary, FEC has been used as an electrolyte additive to adjust the SEI film characteristics of a lithium anode and enhance lithium primary battery performance. The structure and composition of the SEI layer generated on the lithium metal surface can be optimized by an appropriate amount of FEC electrolyte additives in order to significantly improve the storage performance of $\mathrm{Li} / \mathrm{AlF}_{3}$ primary batteries. The FEC additive can improve the specific capacity of the lithium primary battery because of the decomposed, small and dense LiF particles, which can not only provide better protection to the lithium metal, but also conduct lithium ions due to their lithophilic nature. When the FEC content is $5 \%$, an appropriate amount of FEC reacts with the lithium metal before the solvent in the electrolyte to form $\mathrm{LiF}$ and small molecular organic compounds. These products can improve the $\mathrm{Li}^{+}$transport on the lithium surface and change the structure and composition of the SEI film during the discharge process. In particularly, the increase of the LiF particles in the inorganic layer can make the SEI film dense, thereby preventing further contact and reaction of lithium metallic and electrolyte. Consequently, the storage performance of the lithium primary battery may be significantly improved when using a 5\% FEC additive. A FEC-assisted SEI formation strategy is effective to improve electrochemical performance and safety and is a promising technique to be applied to lithium primary batteries, which may be also beneficial for improving the usage and storage characteristics of rechargeable lithium metal batteries.

Supplementary Materials: The following are available online at https:/ /www.mdpi.com/article/10 $.3390 /$ en14227467/s1. Figure S1: SEM images of lithium anodes used in (a) 1\%FEC-RT-7D, (b) 5\%FECRT-7D and (c) 10\%FEC-RT-7D batteries. Figure S2: The surface chemistry of RT-7D battery investigated by XPS. The evolution profiles of (a) atomic percentages and (b) relative elemental intensities along the depth direction. (c,d) XPS spectra of C 1s and Li 1s along the depth direction. (e) The distribution of LiF content along the depth direction.

Author Contributions: Conceptualization, Y.Z.; formal analysis, X.Z. and P.L.; funding acquisition, Y.Z. and X.T.; methodology, X.Z. and P.L.; project administration, Y.Z. and X.T.; software, Z.T.; supervision, S.Z., Y.Z. and X.T.; validation, J.L.; writing—original draft, X.Z. and P.L.; writingreview and editing, Y.Z. and X.T. All authors have read and agreed to the published version of the manuscript.

Funding: This work was supported by the National Natural Science Foundation of China (No. 51974209) and the Postgraduate Innovation Fund Project of Wuhan University of Science and Technology (No. JCX2020005).

Institutional Review Board Statement: Not applicable.

Informed Consent Statement: Not applicable.

Data Availability Statement: The data presented in this study are available on request from the corresponding authors. 
Conflicts of Interest: The authors have no conflict of interest to declare.

\section{References}

1. Raccichini, R.; Varzi, A.; Chakravadhanula, V.; Kübel, C.; Passerini, S. Boosting the power performance of multilayer graphene as lithium-ion battery anode via unconventional doping with in-situ formed Fe nanoparticles. Sci. Rep. 2016, 6, 23585. [CrossRef]

2. Sun, P.-F.; Bai, P.-X.; Chen, Z.-F.; Su, H.; Yang, J.-X.; Xu, K.; Xu, Y.-H. A lithium-organic primary battery. Small 2020, 16, 1906462. [CrossRef]

3. Karaolu, G.; Uzundal, C.-B.; Ulgut, B. Uneven discharge of metallic lithium causes increased voltage noise in $\mathrm{Li} / \mathrm{MnO} 2 \mathrm{primary}$ batteries upon shorting. J. Electrochem. Soc. 2020, 167, 130534. [CrossRef]

4. Zhou, L.; Yang, Y.; Yan, X.-H.; Wang, B.-P.; Zou, Z.-L.; Han, F.-L.; Xue, T. Flexible and free-standing MnOx/reduced graphene oxide paper with excellent cycling stability for Li-ion battery anode. Bull. Mater. Sci. 2020, 43, 271. [CrossRef]

5. Xu, G.-J.; Li, J.-D.; Wang, C.; Du, X.-F.; Lu, D.; Xie, B.; Wang, X.; Lu, C.-L.; Liu, H.-S.; Dong, S.-M.; et al. The formation/decomposition equilibrium of $\mathrm{LiH}$ and its contribution on anode failure in practical lithium metal batteries. Angew. Chem. Int. Ed. 2021, 60, 7770-7776. [CrossRef]

6. Cheng, X.-B.; Zhang, R.; Zhao, C.-Z.; Zhang, Q. Toward safe lithium metal anode in rechargeable batteries: A review. Chem. Rev. 2017, 117, 10403-10473. [CrossRef] [PubMed]

7. Cui, Y.-L.; Liu, S.-F.; Liu, B.; Wang, D.-H.; Zhong, Y.; Zhang, X.-Q.; Wang, X.-L.; Xia, X.-H.; Gu, C.-D.; Tu, J.-P. Bi-containing electrolyte enables robust and $\mathrm{Li}$ ion conductive solid electrolyte interphase for advanced lithium metal anodes. Front. Chem. 2020, 7, 952. [CrossRef]

8. Lee, S.-H.; Hwang, J.-Y.; Ming, J.; Cao, Z.; Nguyen, H.-A.; Jung, H.-G.; Kim, J.; Sun, Y.-K. Toward the sustainable lithium metal batteries with a new electrolyte solvation chemistry. Adv. Energy Mater. 2020, 10, 2000567. [CrossRef]

9. Jie, Y.-L.; Ren, X.-D.; Cao, R.-G.; Cai, W.-B.; Jiao, S.-H. Advanced liquid electrolytes for rechargeable Li metal batteries. Adv. Funct. Mater. 2020, 30, 1910777. [CrossRef]

10. Xia, L.; Yu, L.-P.; Hu, D.; Chen, G.-Z. Electrolytes foe electrochemical energy storage. Mater. Chem. Front. 2017, 1, 584-618. [CrossRef]

11. Young, J.; Kulick, P.-M.; Juran, T.-R.; Smeu, M. Comparative study of ethylene carbonated-based electrolyte decomposition at Li, $\mathrm{Ca}$, and $\mathrm{Al}$ anode interfaces. ACS Appl. Energy Mater. 2019, 2, 1676-1684. [CrossRef]

12. Yang, H.-J.; Guo, C.; Naveed, A.; Lei, J.-Y.; Yang, J.; Nuli, Y.-N.; Wang, L.J. Recent progress and perspective on lithium metal anode protection. Energy Storage Mater. 2018, 14, 199-221. [CrossRef]

13. Zhou, Z.-X.; Feng, Y.-Y.; Wang, J.-L.; Liang, B.; Li, Y.-H.; Song, Z.-X.; Itkis, D.-M.; Song, J.-X. A robust, highly stretchable ion-conducive skin for stable lithium metal batteries. Chem. Eng. J. 2020, 396, 125254. [CrossRef]

14. Wang, W.; Zhang, J.-L.; Yang, Q.; Wang, S.-W.; Wang, W.-H.; Li, B.-H. Stable Cycling of high-voltage lithium-metal batteries enabled by high-concentration FEC-based electrolyte. ACS Appl. Mater. Interfaces 2020, 12, 22901-22909. [CrossRef]

15. Gunnarsdóttir, A.-B.; Vema, S.; Menkin, S.; Marbella, L.-E.; Grey, C.-P. Investigating the effect of a fluoroethylene carbonate additive on lithium deposition and the solid electrolyte interphase in lithium metal batteries using in situ NMR spectroscopy. $J$. Mater. Chem. A 2020, 8, 14975-14992. [CrossRef]

16. Heiskanen, S.-K.; Lucht, B.-L. Fluorinated acetic anhydrides as electrolyte additives to improve cycling performance of the lithium metal anode. J. Electrochem. Soc. 2020, 167, 110506. [CrossRef]

17. Zhang, X.-Q.; Cheng, X.-B.; Chen, X.; Yan, C.; Zhang, Q. Fluoroethylene carbonate additives to render uniform Li deposits in lithium metal batteries. Adv. Funct. Mater. 2017, 27, 1605989. [CrossRef]

18. Bai, Y.; Zhou, Z.-Z.; Zhan, C.; Ma, L.; Yuan, Y.-F.; Wu, C.; Chen, M.-Z.; Chen, G.-H.; Ni, Q.; Wu, F.; et al. 3D hierarchical nano-flake/micro-flower iron fluoride with hydration water induced tunnels for secondary lithium battery cathodes. Nano Energy 2017, 32, 10-18. [CrossRef]

19. Chun, J.; Jo, C.; Sahgong, S.; Kim, M.-G.; Lim, E.; Kim, D.-H.; Hwang, J.; Kang, E.; Ryu, K.-A.; Jung, Y.-S.; et al. Ammonium fluoride mediated synthesis of anhydrous metal fluoride-mesoporous carbon nanocomposites for high-performance lithium ion battery cathodes. ACS Appl. Mater. Interfaces 2016, 8, 35180-35190. [CrossRef] [PubMed]

20. Owen, N.; Zhang, Q. Investigations of aluminum fluoride as a new cathode material for lithium-ion batteries. J. Appl. Electrochem. 2017, 47, 417-431. [CrossRef]

21. Xia, H.; Wang, H.-L.; Xiao, W.; Lai, M.-O.; Lu, L. Thin film Li electrolytes for all-solid-state micro-batteries. Int. J. Surf. Sci. Eng. 2009, 3, 23-43. [CrossRef]

22. Heiskanen, S.-K.; Kim, J.-J.; Lucht, B.-L. Generation and evolution of the solid electrolyte interphase of lithium-ion batteries. Joule 2019, 3, 2322-2333. [CrossRef]

23. Eshkenazi, V.; Peled, E.; Burstein, L.; Golodnitsky, D. XPS analysis of the SEI formed on carbonaceous materials. Solid State Ion. 2004, 170, 83-91. [CrossRef]

24. Luo, Q.; Chao, Y.-J.; Qu, B.; Ma, Z.-F.; Liao, X.-Z. Research technologies of solid electrolyte interphase in Li-ion batteries. Chin. J. Power Sources 2015, 2, 222-226.

25. Wu, X.-J.; He, Z.-Y.; Wang, T.-Q.; Li, X.; Yang, D.-M.; Wang, Q.-S.; Li, Y. Effects of temperature on electrochemical impedance spectroscopy of the $\mathrm{LiFePO}_{4}$ battery. In IOP Conference Series: Earth and Environmental Science; IOP Publishing: Bristol, UK, 2021; Volume 675 , p. 012220. 
26. Zhang, Y.-Z.; Liu, Z.-H.; Wang, Z.; Jiang, Y.-P.; Wen, G.-W.; Gao, P.; Zhu, Y.-M. Electrochemical impedance spectroscopy study of lithium-rich material $0.5 \mathrm{Li}_{2} \mathrm{MnO}_{3} \cdot 0.5 \mathrm{LiNi}_{1 / 3} \mathrm{Co}_{1 / 3} \mathrm{Mn}_{1 / 3} \mathrm{O}_{2}$ in the first two charge-discharge cycles. Electrochim. Acta 2019, 310, 136-145. [CrossRef]

27. Chandrasiri, K.-W.-D.-K.; Nguyen, C.-C.; Zhang, Y.-Z.; Parimalam, B.-S.; Lucht, B.-L. Systematic investigation of alkali metal ions as additives for graphite anode in propylene carbonate based electrolytes. Electrochim. Acta 2017, 20, 285-291. [CrossRef]

28. Lang, J.-L.; Long, Y.-Z.; Qu, J.-L.; Luo, X.-Y.; Wei, H.-H.; Huang, K.; Zhang, H.-T.; Qi, L.-H.; Zhang, Q.-F.; Li, Z.-C.; et al. One-pot solution coating of high quality LiF layer to stabilize Li metal anode. Energy Storage Mater. 2018, 16, 85-90. [CrossRef]

29. Nie, M.-Y.; Abraham, D.-P.; Chen, Y.-J.; Bose, A.; Lucht, B.-L. Anode solid electrolyte interphase (SEI) of lithium-ion battery characterized by microscopy and spectroscopy. J. Phys. Chem. C 2014, 117, 254-263.

30. Marroquín-Cardona, A.; Deng, Y.; Garcia-Mazcorro, J.-F.; Johnson, N.-M.; Mitchell, N.-J.; Tang, L.; Robinson, A.; Taylor, J.-F.; Wang, J.-S.; Phillips, T.-D. Characterization and safety of uniform particle size novasil clay as a potential aflatoxin enterosorbent. Appl. Clay Sci. 2011, 54, 248-257. [CrossRef]

31. Mai, S.-W.; Xu, M.-Q.; Wang, Y.-T.; Liao, X.-L.; Lin, H.-B.; Li, W.-S. Methylene Methanedisulfonate (MMDS) as a novel SEI forming additive on anode for lithium ion batteries. Int. J. Electrochem. Sci. 2014, 9, 6294-6304.

32. Wang, D.; Zhang, W.; Zheng, W.-T.; Cui, X.-Q.; Rojo, T.; Zhang, Q. Towards high-safe lithium metal anodes: Suppressing lithium dendrites via tuning surface energy. Adv. Sci. 2017, 4, 1600168. [CrossRef] [PubMed]

33. Chen, C.; Liang, Q.-W.; Wang, G.; Liu, D.-D.; Xiong, X.-H. Grain-boundary-rich artificial SEI layer for high-rate lithium metal anodes. Adv. Funct. Mater. 2021. [CrossRef]

34. Lei, W.-Y.; Liu, Y.-Y.; Jiao, X.-X.; Zhang, C.-F.; Xiong, S.-Z.; Li, B.; Song, J.-X. Improvement of cycling phosphorus-based anode with LiF-rich solid electrolyte interphase for reversible lithium storage. ACS Appl. Energy Mater. 2019, 2, 2699-2707. [CrossRef]

35. Huang, Z.-H.; Li, X.; Wang, Q.-S.; Duan, Q.-L.; Li, Y.; Li, L.-N.; Wang, Q.-S. Experimental investigation on thermal runaway propagation of large format lithium-ion battery modules with two cathodes. Int. J. Heat Mass Transf. 2021, 172, 121077. [CrossRef]

36. Liu, Q.; Cresce, A.; Schroeder, M.; Xu, K.; Mu, D.-B.; Wu, B.-R.; Shi, L.-L.; Wu, F. Insight on lithium metal anode interphasial chemistry: Reduction mechanism of cyclic ether solvent and SEI film formation. Energy Storage Mater. 2019, 17, 366-373. [CrossRef]

37. Yan, C.; Cheng, X.-B.; Tian, Y.; Chen, X.; Zhang, X.-Q.; Li, W.-J.; Huang, J.-Q.; Zhang, Q. Dual-layered film protected lithium metal anode to enable dendrite-free lithium deposition. Adv. Mater. 2018, 30, 1707629. [CrossRef] [PubMed] 